Check for updates

Cite this: RSC Adv., 2019, 9, 32510

Received 20th August 2019 Accepted 28th September 2019

DOI: 10.1039/c9ra06514h

rsc.li/rsc-advances

\title{
Transition metal oxideahydroxide assemblies as electrode materials for asymmetric hybrid capacitors with excellent cycling stabilities
}

\begin{abstract}
Pengfei Hu, ${ }^{a}$ Ying Liu, ${ }^{a}$ Jianrong Song, ${ }^{a}$ Xiufeng Song ${ }^{b}$ and Xiang Wu (D) *a
In this work, three-dimensional cactus-like $\mathrm{CO}_{3} \mathrm{O}_{4} \mathrm{aNi}(\mathrm{OH})_{2}$ electrode materials are grown directly on $\mathrm{Ni}$ foam via a two-step hydrothermal method. The as-prepared products possess a specific capacitance of $464.5 \mathrm{C} \mathrm{g}^{-1}$ at $0.5 \mathrm{~A} \mathrm{~g}^{-1}$ and $91.67 \%$ capacitance retention after 20000 cycles. The as-assembled device using the as-synthesized samples as positive electrodes delivers an energy density of $112.5 \mathrm{~W} \mathrm{~h} \mathrm{~kg}^{-1}$ at a power density of $1350 \mathrm{~W} \mathrm{~h} \mathrm{~kg}^{-1}$. The superior electrochemical performance of the electrode materials can be attributed to their unique structure, the synergistic effect between $\mathrm{CO}_{3} \mathrm{O}_{4}$ and $\mathrm{Ni}(\mathrm{OH})_{2}$ materials and reversible reaction kinetics. It suggests that the products are potential alternatives in future energy storage devices.
\end{abstract}

\section{Introduction}

With the increasing depletion of fossil fuels and serious environmental pollution, to develop and design clean, renewable energy sources and emerging energy storage devices is a very imperious task..$^{1-4}$ Among them, supercapacitors have attracted increasing attention due to their fast charging-discharging, high power density, long cycle life and environmental friendly characteristics. ${ }^{5-8}$ Carbon materials and conductive polymers with high specific surface area and low internal resistance have been widely investigated. For example, Fang and co-workers reported hierarchical porous carbon nanorods with a capacitance of $274 \mathrm{~F} \mathrm{~g}^{-1}$ at $0.5 \mathrm{~A} \mathrm{~g}^{-1}{ }^{-9}$ Liu et al. prepared $\mathrm{MoS}_{2} / \mathrm{Ni}_{3}$ $\mathrm{S}_{2} @ P$ Py samples showing a specific capacitance of $845 \mathrm{C} \mathrm{g}^{-1}$ at $1 \mathrm{~A} \mathrm{~g}^{-1} \cdot{ }^{10}$ However, poor cycling stability hinders their further application. Therefore, it is urgent to develop novel electrode materials with the desired architectures and properties.

As electrode materials, transition metal oxides and hydroxides possess large theoretical capacity and accessible active sites for redox reaction. ${ }^{11-21}$ Therein $\mathrm{Co}_{3} \mathrm{O}_{4}$ materials possess a theoretical capacitance of $3500 \mathrm{~F} \mathrm{~g}^{-1}$ and tailoring spatial structures. ${ }^{22,23}$ Many research groups have reported $\mathrm{Co}_{3} \mathrm{O}_{4}$ structures as electrode materials with various shapes and structures for capacitors. For instance, Zhang et al. in situ synthesized $\mathrm{Co}_{3} \mathrm{O}_{4}$ samples by a facile hydrothermal reaction with a capacitance of $621.8 \mathrm{~F} \mathrm{~g}^{-1}$ at $1 \mathrm{~A} \mathrm{~g}^{-1} .{ }^{24}$ Chen and co-worker reported $\mathrm{Co}_{3} \mathrm{O}_{4}$ nanorod arrays by chemical bath deposition showing a capacitance of $387.25 \mathrm{~F} \mathrm{~g}^{-1}$ at $1 \mathrm{~A} \mathrm{~g}^{-1} \cdot{ }^{25}$ Gao et al. prepared $\mathrm{Co}_{3} \mathrm{O}_{4}$

${ }^{a}$ School of Materials Science and Engineering, Shenyang University of Technology, Shenyang110870, P. R. China.E-mail:wuxiang05@163.com; wuxiang05@sut.edu.cn ${ }^{b}$ School of Materials Science and Engineering, Nanjing University of Science and Technology, Nanjing, P. R. China nanowires using a template-free process and obtained a capacitance of $746 \mathrm{~F} \mathrm{~g}^{-1}$ at $1 \mathrm{~A} \mathrm{~g}^{-1} .{ }^{26}$ Nevertheless, the practical capacity is far lower than their theoretical one, which limits their future applications in energy storage fields. ${ }^{27,28}$ Thus, to construct hybrid electrode materials with unique spatial architectures and high capacity is very important.

Two dimensional layered $\mathrm{Ni}(\mathrm{OH})_{2}$ nanostructures enable fast diffusion of electrons, which make active sites for redox reaction easily accessible. ${ }^{29-31}$ For example, Yang's group reported $\mathrm{Ni}(\mathrm{OH})_{2}$ electrode exhibiting a specific capacitance of $2110 \mathrm{~F} \mathrm{~g}^{-1}$ at $1 \mathrm{~A} \mathrm{~g}^{-1} \cdot{ }^{32}$ Xiong et al. synthesized $\mathrm{Ni}(\mathrm{OH})_{2}$ nanosheets with a capacitance of $2384.3 \mathrm{~F} \mathrm{~g}^{-1}$ at $1 \mathrm{~A} \mathrm{~g}^{-1}{ }^{33}$ Dai et al. prepared $\mathrm{Ni}(\mathrm{OH})_{2}$ nanocrystals grown on graphene sheets showing a capacitance of $1335 \mathrm{~F} \mathrm{~g}^{-1}$ at $1 \mathrm{~A} \mathrm{~g}^{-1} \cdot{ }^{34}$ Herein, we design a kind of cactus-like $\mathrm{Co}_{3} \mathrm{O}_{4} @ \mathrm{Ni}(\mathrm{OH})_{2}$ structure on $\mathrm{Ni}$ foam through a facile two-step hydrothermal approach. The as-prepared products show a specific capacitance of $464.5 \mathrm{C} \mathrm{g}^{-1}$ at $0.5 \mathrm{~A} \mathrm{~g}^{-1}$ and $91.67 \%$ of capacitance retention after 20000 cycles. A capacitor is assembled using $\mathrm{Co}_{3} \mathrm{O}_{4} @ \mathrm{Ni}(\mathrm{OH})_{2}$ as positive electrode and active carbon as negative electrode, respectively. It delivers an energy density of $112.5 \mathrm{~W} \mathrm{~h} \mathrm{~kg}^{-1}$ at power density of $1350 \mathrm{~W} \mathrm{~kg}^{-1}$. The excellent performance could be attributed to fast ion transport channel, which constructed by direct contact between two materials and synergistic effect.

\section{Experimental}

All the chemicals in this work are of analytical grade and directly used without further purification. Ni foam was treated, which is similar to our previous report. ${ }^{35} \mathrm{In}$ a typical procedure, $3 \mathrm{mmol} \mathrm{Co}\left(\mathrm{NO}_{3}\right)_{2} \cdot 6 \mathrm{H}_{2} \mathrm{O}(0.8731 \mathrm{~g}), 4 \mathrm{mmol} \mathrm{NH}_{4} \mathrm{~F}(0.1482 \mathrm{~g})$ and $10 \mathrm{mmol} \mathrm{CO}\left(\mathrm{NH}_{2}\right)_{2}(0.6006 \mathrm{~g})$ were dissolved in $50 \mathrm{~mL}$ deionized water and stirred to form a homogeneous solution. Then 
the above solution was transferred into a $100 \mathrm{~mL}$ autoclave and a piece of pretreated Ni foam was immersed into it. The autoclave was sealed and heated at $120^{\circ} \mathrm{C}$ for $6 \mathrm{~h}$. After cooling down to room temperature naturally, the Ni foam was taken out and washed with ethanol and deionized water for three times, respectively, to remove possible impurities or excess ions. After that, it was dried at $60{ }^{\circ} \mathrm{C}$ for $12 \mathrm{~h}$. Subsequently, the asprepared samples were obtained by annealing at $350{ }^{\circ} \mathrm{C}$ for $2 \mathrm{~h}$. The average mass loading is $2.1 \mathrm{mg} \mathrm{cm}^{-2}$. Then $\mathrm{Ni}$ foam coated $\mathrm{Co}_{3} \mathrm{O}_{4}$ nanowires were immersed into solution of $\mathrm{Ni}\left(\mathrm{NO}_{3}\right)_{2}$ and transferred to same volume of autoclave at $120^{\circ} \mathrm{C}$ for $8 \mathrm{~h}$. After cooled to room temperature, the as-prepared samples were cleaned and then dried at $60{ }^{\circ} \mathrm{C}$ for $12 \mathrm{~h}$. The mass loading is $4.8 \mathrm{mg} \mathrm{cm}^{-2}$.

The morphology and crystal structure of as-prepared products were analyzed using an X-ray diffraction analyzer (XRD, Shimadzu 7000, $\mathrm{Cu} \mathrm{K} \alpha$ radiation, $\lambda=0.15406 \mathrm{~nm}, 40 \mathrm{kV}$ ), scanning electron microscope (SEM; Gemini SEM 300-71-31). Element compositions were studied by element mappings. The chemical states of products were recorded by X-ray photoelectron (ESCALAB 250).

Electrochemical performances of the as-synthesized products were investigated on a workstation (Shanghai Chenhua, CHI660E) in a three-electrode system. The samples were used as working electrode, $\mathrm{Hg} / \mathrm{HgO}$ as reference one and $\mathrm{Pt}$ foil as counter one. Cyclic voltammetry (CV), galvanostatic chargedischarge (GCD) and electrochemical impedance spectroscopy (EIS) measurements were conducted in $3 \mathrm{M} \mathrm{KOH}$ aqueous electrolyte. Specific capacitance $\left(C_{\mathrm{s}}\right)$ was obtained from GCD curves according to following equation:

$$
C_{\mathrm{s}}=I \Delta t / m
$$

where $I(\mathrm{~A})$ is discharge current, $\Delta t(\mathrm{~s})$ refers to discharge time, and $m(\mathrm{~g})$ represents the mass loading of electrode.

Activated carbon, super $\mathrm{p}$ and polyvinylidene difluoride (PVDF) with a mass ratio of $7: 2: 1$ were mixed on $\mathrm{Ni}$ foam as negative electrode for supercapacitor. Quasi-solid-state polyvinyl alcohol (PVA)-KOH electrolyte was made by mixing $2 \mathrm{~g}$ PVA and $2 \mathrm{~g} \mathrm{KOH}$ in $20 \mathrm{~mL}$ deionized water. The mass loading of active carbon was calculated based on charge balance theory $\left(Q^{+}\right.$ $=Q^{-}$), where $Q^{+}$and $Q^{-}$represents stored charges that can be calculated as follow:

$$
Q=C_{\mathrm{s}} \times \Delta V \times m
$$

where $C_{\mathrm{s}}$ is specific capacitance $\left(\mathrm{C} \mathrm{g}^{-1}\right), \Delta V$ refers voltage window, $m$ names the mass loading of active materials $(\mathrm{g})$. The mass ratio of active materials can be obtained by following equation:

$$
m^{+} / m^{-}=C_{\mathrm{s}}^{-} \times \Delta V^{-} / C_{\mathrm{s}}^{+} \times \Delta V^{+}
$$

The optimal mass ratio of $\mathrm{Co}_{3} \mathrm{O}_{4} @ \mathrm{Ni}(\mathrm{OH})_{2} / / \mathrm{AC}$ is 0.45 . Energy density $E\left(\mathrm{~W} \mathrm{~h} \mathrm{~kg}^{-1}\right)$ and power density $P\left(\mathrm{~W} \mathrm{~kg}^{-1}\right)$ of the device can be calculated from the equations:

$$
E=1 / 2 \times C_{\mathrm{s}} \times \Delta V^{2}
$$

$$
P=E \times 3600 / \Delta t
$$

where $\Delta V(\mathrm{~V})$ is voltage window of device, $\Delta t(\mathrm{~s})$ is discharge time.

\section{Results and discussion}

The phase purity and crystal structure of products are firstly characterized by XRD, as shown in Fig. 1a. All diffraction peaks (black line) of samples located at $19.0^{\circ}(111), 31.2^{\circ}(220), 36.8^{\circ}$ (311), 38.5 ${ }^{\circ}(222), 55.6^{\circ}(422), 59.3^{\circ}(511)$ and $65.2^{\circ}(440)$ can be indexed to $\mathrm{Co}_{3} \mathrm{O}_{4}$ (JCPDS No.42-1467). The diffraction peaks (red line) at $19.2^{\circ}, 33.1^{\circ}, 39.1^{\circ}, 59.1^{\circ}$ and $62.7^{\circ}$ correspond to (001), (100), (002), (110), (111) crystal planes, which can be assigned to $\mathrm{Ni}(\mathrm{OH})_{2}$ (JCPDS No.14-0117). From the diffraction peaks (blue line), $\mathrm{Co}_{3} \mathrm{O}_{4} @ \mathrm{Ni}(\mathrm{OH})_{2}$ products are successful prepared.

XPS is used to further study elemental composition and chemical states of products. The survey spectra (Fig. 1b) show the presence of $\mathrm{Co}, \mathrm{Ni}$ and $\mathrm{O}$ elements. $\mathrm{C}$ is from the base. The de-convolution of Ni 2p XPS spectra in Fig. 1c presents two characteristic peaks of $\mathrm{Ni} 2 \mathrm{p}_{3 / 2}$ and $\mathrm{Ni} 2 \mathrm{p}_{1 / 2}$ at 855.5 and $873.1 \mathrm{eV}$ and two satellite peaks at 862 and $879 \mathrm{eV}$, respectively. ${ }^{36}$ Fig. 1d indicates that Co 2 p spectra consist of $\mathrm{Co}^{2+}$ and $\mathrm{Co}^{3+}$. It could be de-convoluted into two sharp peaks and two satellite peaks. The peaks at 779.3 and $794.5 \mathrm{eV}$ are related to $\mathrm{Co}^{3+}$ and those at 781 and $796.2 \mathrm{eV}$ might be ascribed to $\mathrm{Co}^{2+} .^{37}$ The peaks of O 1s spectra (Fig. 1e) at 529.7, 531.2 and $532.5 \mathrm{eV}$ are associated with metal-oxygen bond, hydroxyl $\left(\mathrm{OH}^{-}\right)$and surface absorbed water, respectively. ${ }^{38}$ Elemental distributions of products are also investigated by element mappings, demonstrating that elements are uniformly distributed on the Ni foam, as shown in Fig. 1f.

Fig. 2a is SEM images of as-prepared $\mathrm{Co}_{3} \mathrm{O}_{4}$ products. It shows that they consist of many nanowires. Further observation (Fig. 2d) finds that the average diameter of the nanowires is $70 \mathrm{~nm}$. Fig. 2b shows SEM images of $\mathrm{Ni}(\mathrm{OH})_{2}$ sample, revealing that dense sheet-like structures appear. Local images can be seen in Fig. 2e. From SEM images shown in Fig. 2(c and f), it is found that hybrid materials consist of many nanowires and nanosheets that interconnect with each other to form unique three-dimensional cactus-like structures.

Electrochemical performances of as-synthesized products are studied in $3 \mathrm{M} \mathrm{KOH}$ aqueous solution in a three-electrode system. Fig. 3a-c show CV curves of three electrodes at scan rate from 5 to $50 \mathrm{mV} \mathrm{s}^{-1}$. $\mathrm{CV}$ curves of composite electrode present a pair of redox peaks, revealing that capacitive behavior of electrode materials. The redox peaks correspond to faradaic redox reactions during charging-discharging process as follows: $:^{39,40}$

$$
\begin{gathered}
\mathrm{Co}_{3} \mathrm{O}_{4}+\mathrm{OH}^{-}+\mathrm{H}_{2} \mathrm{O} \leftrightarrow 3 \mathrm{CoOOH}+\mathrm{e}^{-} \\
\mathrm{CoOOH}+\mathrm{OH}^{-} \leftrightarrow \mathrm{CoO}_{2}+\mathrm{H}_{2} \mathrm{O}+\mathrm{e}^{-} \\
\mathrm{Ni}(\mathrm{OH})_{2}+\mathrm{OH}^{-} \leftrightarrow \mathrm{NiOOH}+\mathrm{H}_{2} \mathrm{O}+\mathrm{e}^{-}
\end{gathered}
$$



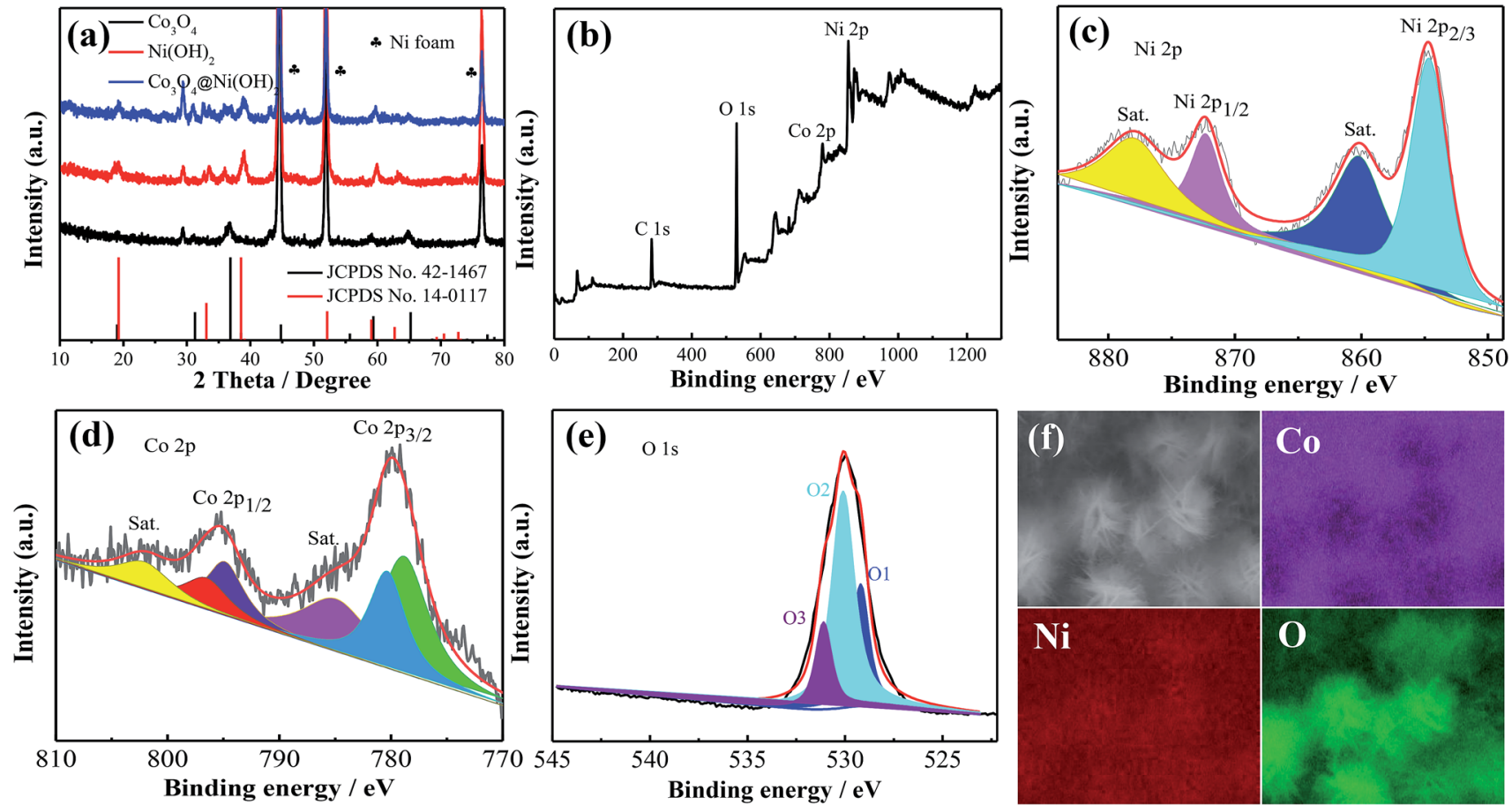

Fig. 1 (a) XRD patterns of the products and XPS spectra of $\mathrm{CO}_{3} \mathrm{O}_{4}\left(\mathrm{aNi}(\mathrm{OH})_{2}\right.$ sample (b) survey spectra (c) $\mathrm{Ni} 2 \mathrm{p}$ (d) $\mathrm{Co} 2 \mathrm{p}$ (e) O $1 \mathrm{~s}$ (f) EDS of the composites.

The shapes of CV curves maintains well, indicating excellent reversibility of redox reaction. The corresponding GCD curves of samples are shown in Fig. 3d-f. According to GCD curves of hybrid electrodes at various current densities, specific capacitances are $464.5,407,322,240$, and $180 \mathrm{C} \mathrm{g}^{-1}$ at $0.5,1,2,4$ and $6 \mathrm{~A} \mathrm{~g}^{-1}$, respectively.
Fig. 4a shows CV curves of as-synthesized products and pure $\mathrm{Ni}$ foam at $20 \mathrm{mV} \mathrm{s}^{-1}$. Obviously, the effect of pure $\mathrm{Ni}$ foam on capacities of the samples can be neglected due to its insignificant contribution. It is accordance with previous reports. ${ }^{\mathbf{4 1}}$ The integrated area of $\mathrm{CV}$ curve of $\mathrm{Co}_{3} \mathrm{O}_{4} @ \mathrm{Ni}(\mathrm{OH})_{2}$ samples is relatively larger, suggesting that composite electrode possesses a high capacitance. Fig. 4b shows GCD curves of three electrode
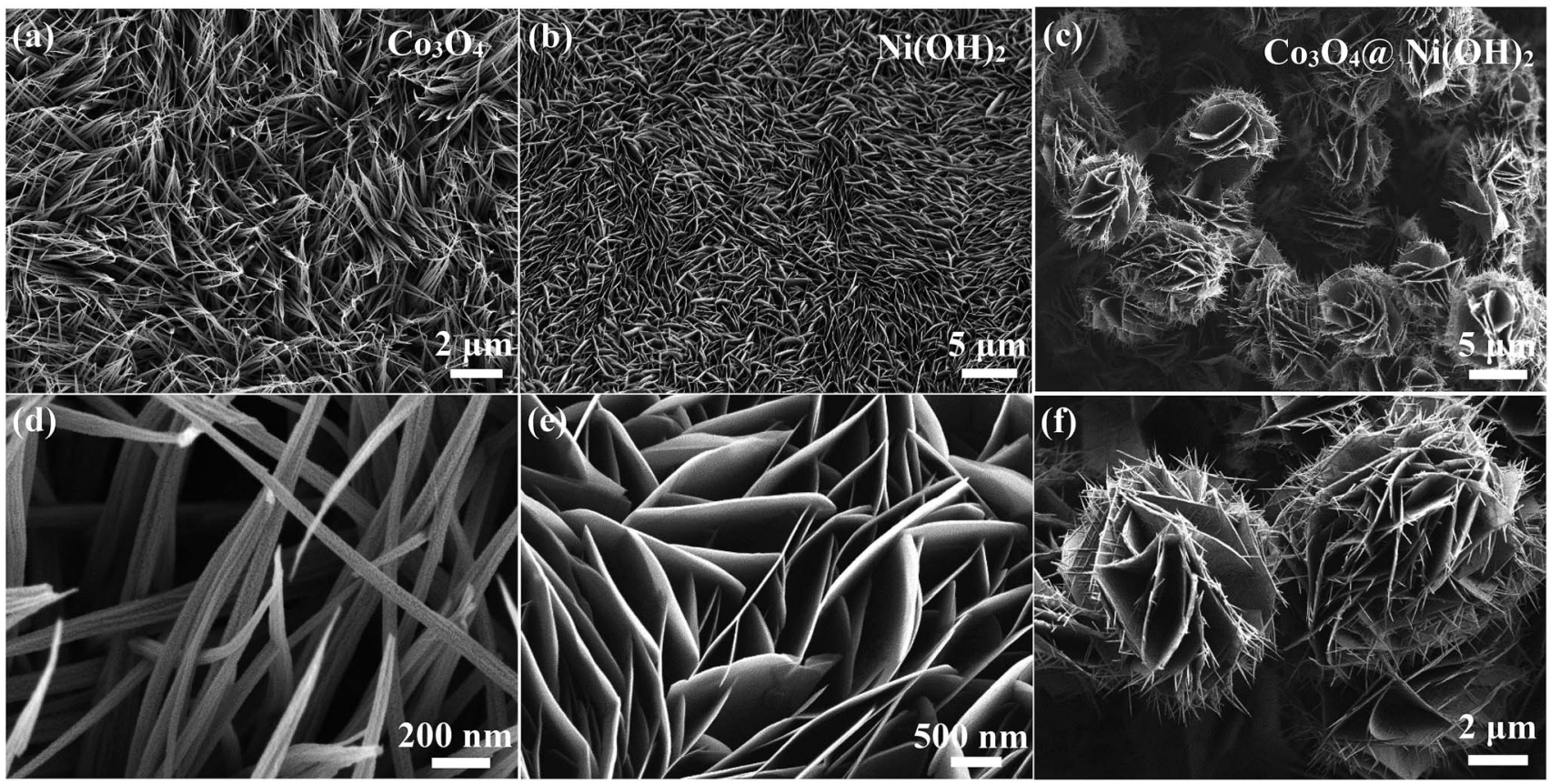

Fig. 2 SEM images of the samples (a and d) $\mathrm{Co}_{3} \mathrm{O}_{4}\left(\mathrm{~b}\right.$ and e) $\mathrm{Ni}(\mathrm{OH})_{2}$ (c and f) $\mathrm{CO}_{3} \mathrm{O}_{4}\left(\mathrm{Ni}(\mathrm{OH})_{2}\right.$. 

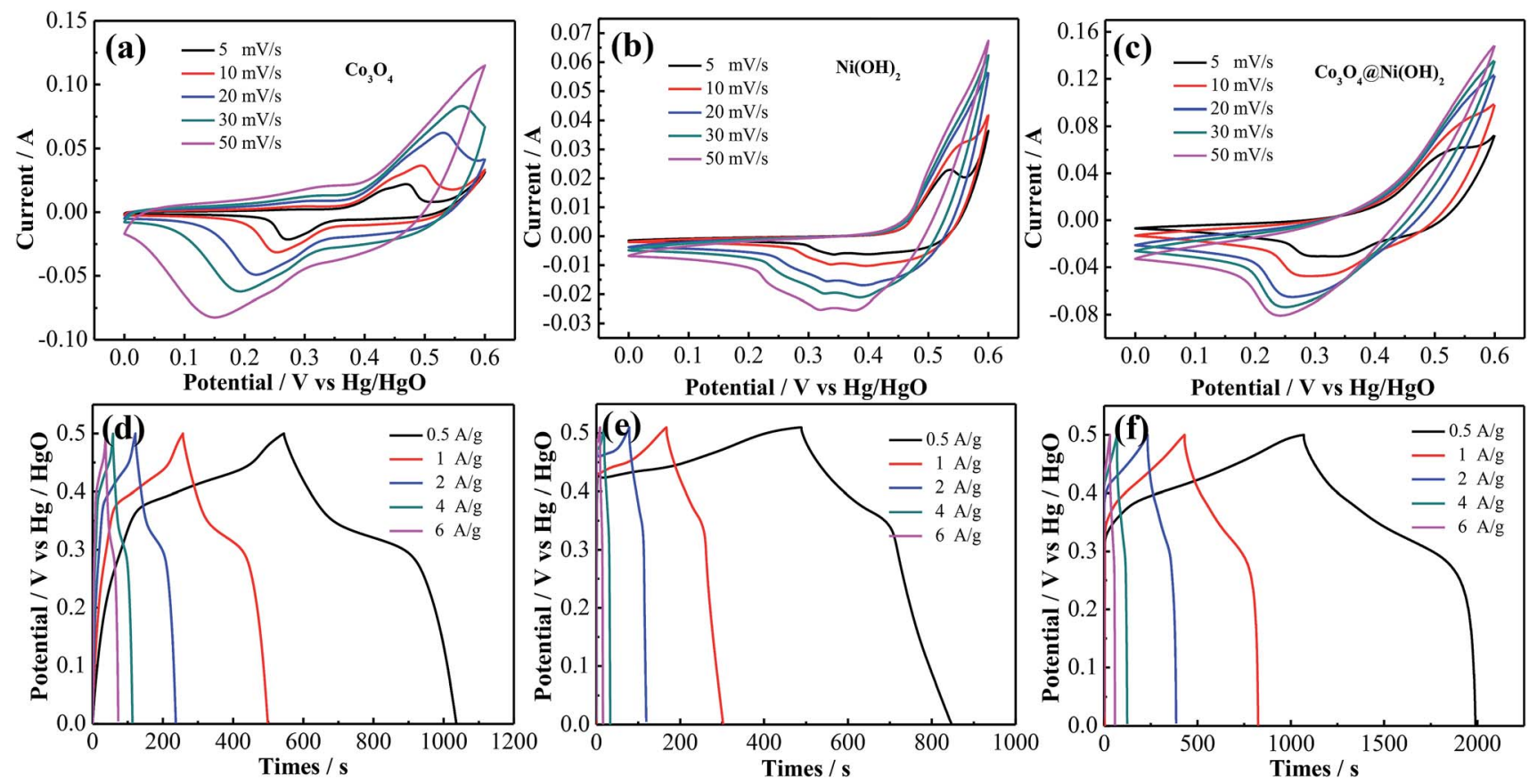

Fig. 3 Electrochemical performance of three electrodes ( $a-c)$ CV curves (d-f) GCD curves.

materials at the same current density. The discharge time of hybrid electrode is longer than two other samples.

To further investigate the conductivity of as-synthesized products, EIS are conducted within frequency range from 0.01 to $10^{5} \mathrm{~Hz}$. Fig. $4 \mathrm{c}$ demonstrates Nyquist plots of all samples, which include a semicircle at high frequency region and a straight line at low frequency one. The former represents equivalent series resistance $\left(E_{\mathrm{SR}}\right)$, the latter corresponds to Warburg resistance. $E_{\mathrm{SR}}$ of $\mathrm{Co}_{3} \mathrm{O}_{4} @ \mathrm{Ni}(\mathrm{OH})_{2}, \mathrm{Co}_{3} \mathrm{O}_{4}, \mathrm{Ni}(\mathrm{OH})_{2}$ are $0.74,0.88,1.45 \mathrm{ohm} \mathrm{cm}{ }^{-2}$, respectively, suggesting that hybrid electrode possesses a low internal resistance.
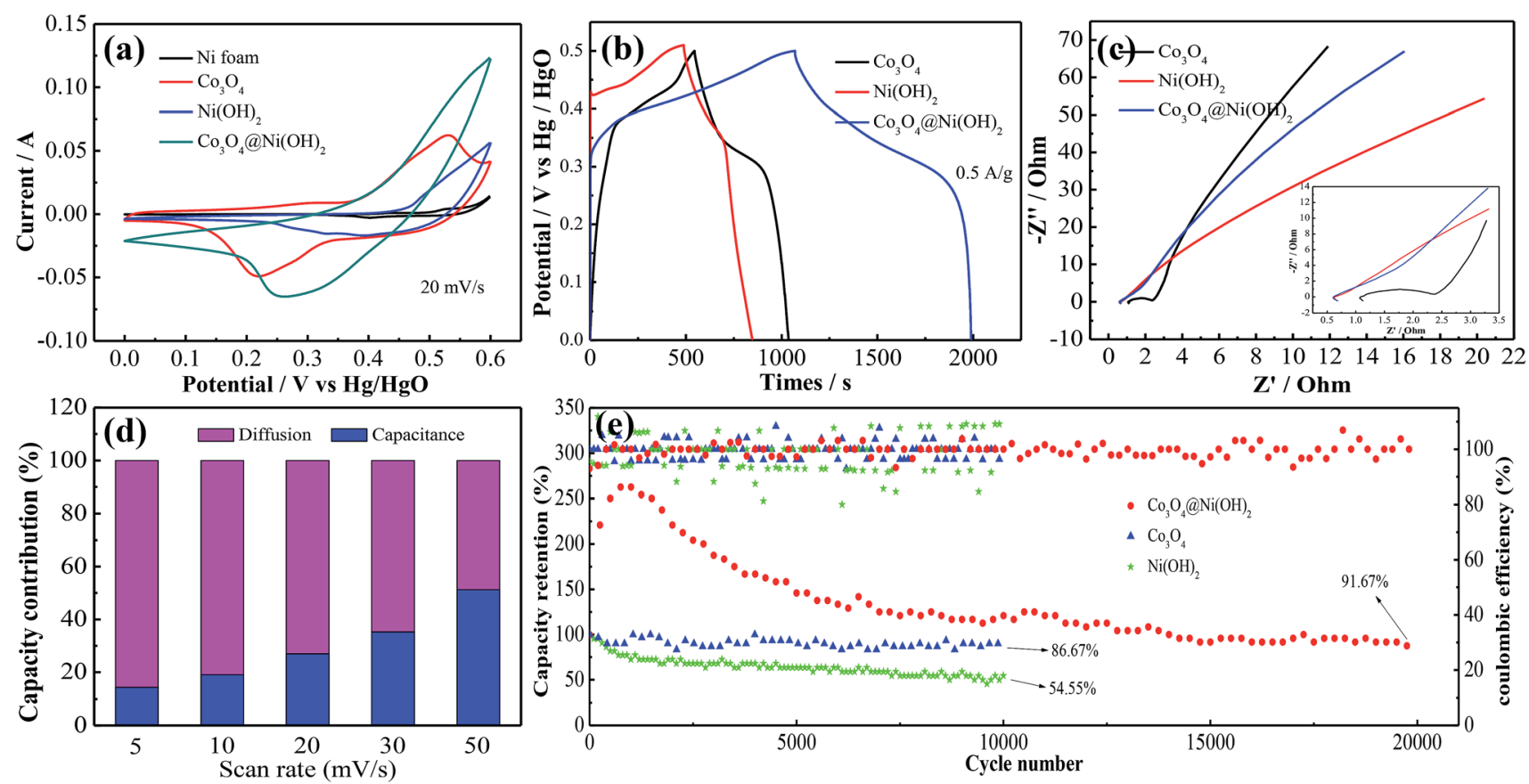

Fig. 4 Electrochemical performance of the electrodes (a) CV curves (b) GCD curves (c) Nyquist plots (d) contribution ratio between diffusion and capacitance (e) cycling performance. 

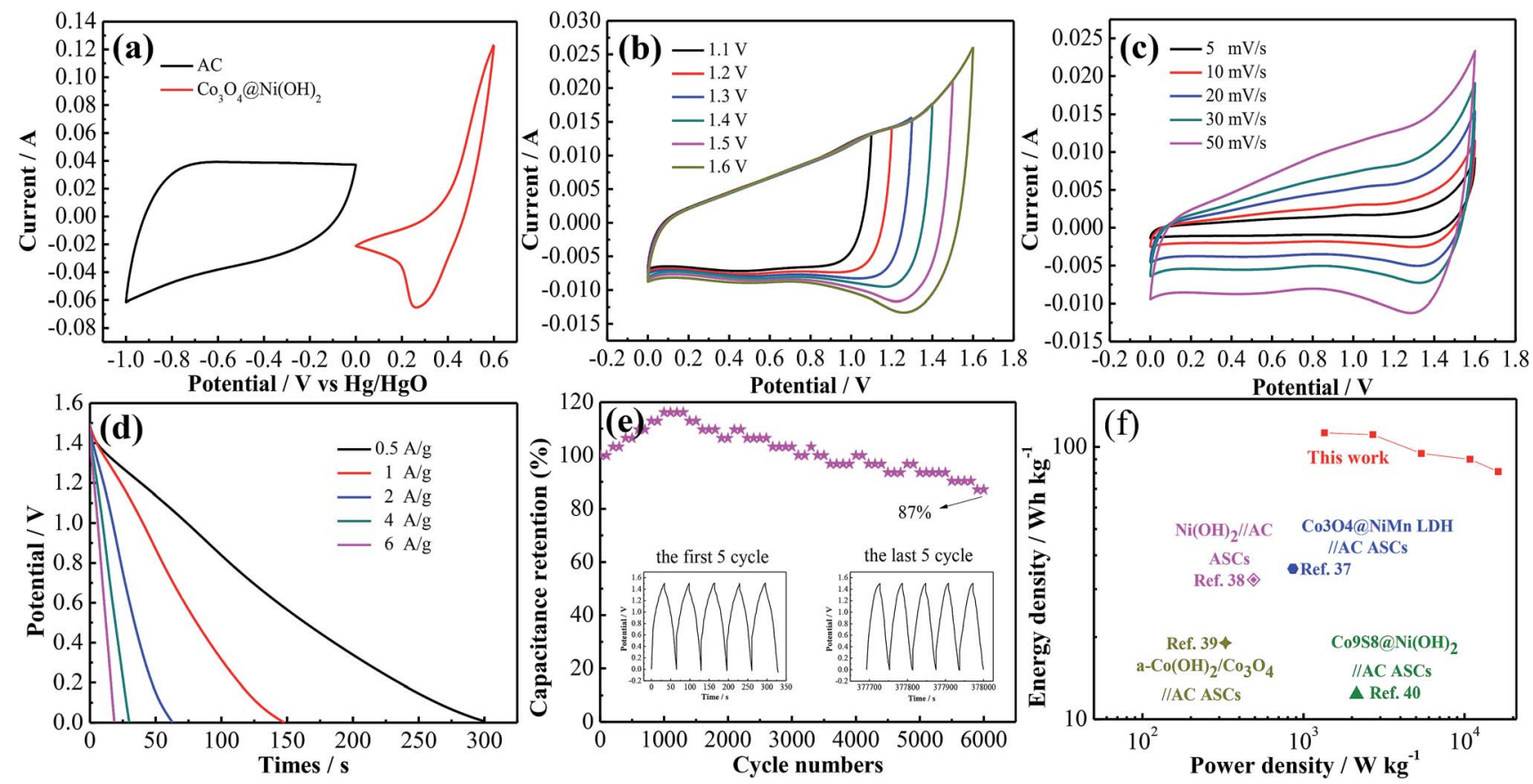

Fig. 5 (a) $\mathrm{CV}$ curves of $\mathrm{CO}_{3} \mathrm{O}_{4} \mathrm{aNi}(\mathrm{OH})_{2}$ and $\mathrm{AC}$ electrode at $20 \mathrm{mV} \mathrm{s}^{-1}$ (b and c) CV curves of device (d) GCD curves (e) cycling performance (f) Ragone plot.

To understand surface and diffusion behavior of electrodes, the normalization formulas for CV kinetics analysis are listed as follows: ${ }^{42}$

$$
\begin{gathered}
i=a v^{b} \\
i / v^{1 / 2}=a v^{1 / 2}+b
\end{gathered}
$$

where $a$ and $b$ are constants, $i$ and $v$ represent current and scan rate, respectively. As shown in Fig. 4d, diffusion controlled contribution is dominant, revealing that battery-type behavior of electrode materials. Cycling stabilities (Fig. 4e) of assynthesized samples are investigated at $6 \mathrm{~A} \mathrm{~g}^{-1}$. It can be seen that the capacitance retention ratio of hybrid electrode can reach $91.67 \%$ after 20000 cycles, which is much higher than other two ones. The excellent cycling stability might benefit from synergistic effect between two electrodes. The activation of electrode materials results in the increases of specific capacitance in the initial cycles. With the adding of cycle times, electrode materials are gradually infiltrated by electrolyte, which results in an increase in capacitance.
To estimate its practical application, a hybrid capacitor is assembled using as-prepared products and active carbon as positive and negative electrodes, respectively. CV curves of two electrodes show stable voltage windows between 0 and $0.6 \mathrm{~V}$ and between -1 and $0 \mathrm{~V}$, respectively (Fig. 5a). The curves at $50 \mathrm{mV} \mathrm{s}^{-1}$ indicate that the device can work at $1.6 \mathrm{~V}$, as shown in Fig. 5 b. CV curves of device at scan rates from 5 to $50 \mathrm{mV} \mathrm{s}^{-1}$ (Fig. 5c) exhibits that it possesses ideal capacitive performance. According to GCD curves at various current densities (Fig. 5d), the device delivers a capacitance of $150 \mathrm{C} \mathrm{g}^{-1}$ at $0.5 \mathrm{~A} \mathrm{~g}^{-1}$. It keeps $87 \%$ of initial capacitance after 6000 cycles in Fig. 5e.

Energy density and power density of device are two significant parameters in actual applications. Fig. 5f shows Ragone plots of some devices. The device presents an energy density of $112.5 \mathrm{~W} \mathrm{~h} \mathrm{~kg}^{-1}$ at power density of $1350 \mathrm{~W} \mathrm{~kg}^{-1}$, which are better than some previous reports. ${ }^{\mathbf{4 0 , 4 3 - 4 5}}$ According to Table 1, the hybrid electrode materials reported here possess high specific capacitance and excellent cycling stability. ${ }^{23,46-49}$

\begin{tabular}{|c|c|c|c|c|}
\hline Materials & Specific capacitance $\left(1 \mathrm{~A} \mathrm{~g}^{-1}\right)$ & Electrolyte & Retention rate & Ref. \\
\hline $\mathrm{Co}_{3} \mathrm{O}_{4}$ mesoporous nanoneedle & $668 \mathrm{~F} \mathrm{~g}^{-1}\left(367.4 \mathrm{C} \mathrm{g}^{-1}\right)$ & $2 \mathrm{M} \mathrm{KOH}$ & 104\% (10 000 cycles) & 23 \\
\hline$\alpha-\mathrm{Co}(\mathrm{OH})_{2} / \mathrm{Co}_{3} \mathrm{O}_{4}$ flakes & $583 \mathrm{~F} \mathrm{~g}^{-1}\left(291.5 \mathrm{C} \mathrm{g}^{-1}\right)$ & $2 \mathrm{M} \mathrm{KOH}$ & $87.6 \%$ (1000 cycles) & 46 \\
\hline Sandwich-like $\mathrm{Co}_{3} \mathrm{O}_{4} / \mathrm{CNTs}$ & $562 \mathrm{~F} \mathrm{~g}^{-1}\left(252.9 \mathrm{C} \mathrm{g}^{-1}\right)$ & $3 \mathrm{M} \mathrm{KOH}$ & $96 \%(5000$ cycles $)$ & 47 \\
\hline $2 \mathrm{D} \mathrm{MoSe}_{2}-\mathrm{Ni}(\mathrm{OH})_{2}$ nanohybrid & $933 \mathrm{~F} \mathrm{~g}^{-1}\left(419 \mathrm{C} \mathrm{g}^{-1}\right)$ & $6 \mathrm{M} \mathrm{KOH}$ & $91.6 \%$ (5000 cycles) & 48 \\
\hline $\mathrm{Co}_{3} \mathrm{O}_{4}$ nanosheets & $581 \mathrm{~F} \mathrm{~g}^{-1}\left(261.4 \mathrm{C} \mathrm{g}^{-1}\right)$ & $2 \mathrm{M} \mathrm{KOH}$ & $91 \%(5000$ cycles $)$ & 49 \\
\hline $\mathrm{Co}_{3} \mathrm{O}_{4} @ \mathrm{Ni}(\mathrm{OH})_{2}$ cactus & $407 \mathrm{C} \mathrm{g}^{-1}$ & $3 \mathrm{M} \mathrm{KOH}$ & $91.67 \%$ (20 000 cycles $)$ & This work \\
\hline
\end{tabular}

Table 1 Electrochemical performance comparison of various electrode materials 


\section{Conclusion}

In summary, we have fabricated a kind of cactus-like $3 \mathrm{D} \mathrm{Co}_{3}$ $\mathrm{O}_{4} @ \mathrm{Ni}(\mathrm{OH})_{2}$ structure on Ni foam via two-step hydrothermal process. Benefiting from the unique architecture, the asobtained products possess superior electrochemical performances due to the synergistic effects between two single materials. Moreover, the device presents high energy density and excellent cycling stability. It demonstrates that the hybrid architectures can be used as alternative electrode materials in high-performance energy storage devices.

\section{Conflicts of interest}

There are no conflicts to declare.

\section{Acknowledgements}

This project is supported by the Fundamental Research Funds for the Central Universities (No 30919011410).

\section{Notes and references}

1 L. Kouchachvili, W. Yaici and E. Entchev, J. Power Sources, 2018, 473, 237-248.

2 C. C. Duan, R. J. Kee, H. Y. Zhu, C. Karakaya, Y. C. Chen, S. Ricote, A. Jarry, E. J. Crumlin, D. Hook and R. Braun, Nature, 2018, 557, 217-222.

3 D. Prochowicz, M. M. Tavakoli, S.-H. Turren-Cruz, K. Pandey, M. Saliba and P. Yadav, Sustainable Energy Fuels, 2018, 2, 2407-2411.

4 D. Chen, Z. Lou, K. Jiang and G. Z. Shen, Adv. Funct. Mater., 2018, 28, 1805596.

5 Y. Zhou, H. J. Guo, G. C. Yan, Z. X. Wang, X. H. Li, Z. W. Yang, A. X. Zheng and J. X. Wang, Chem. Commun., 2018, 54, 37553758.

6 D. P. Zhao, H. Q. Liu and X. Wu, Nano Energy, 2019, 57, 363370.

7 W. H. Zuo, R. Z. Li, C. Zhou, Y. Y. Li, J. L. Xia and J. P. Liu, Adv. Sci., 2017, 4, 1600539.

8 X. Wu, Z. C. Han, X. Zheng, S. Y. Yao, X. Yang and T. Y. Zhai, Nano Energy, 2017, 31, 410-417.

9 L. Fang, Y. P. Xie, Y. Y. Wang, Z. W. Zhang, P. F. Liu, N. A. Cheng, J. F. Liu, Y. C. Tu, H. B. Zhao and J. J. Zhang, Appl. Surf. Sci., 2019, 464, 479-487.

10 Y. Liu, P. F. Hu, J. R. Song, A. Umar and X. Wu, Inorg. Chem. Front., 2019, 6, 2824-2831.

11 K. S. Ashutosh and S. Debasish, J. Mater. Chem. A, 2017, 5, 21715-21725.

12 W. T. Sun, L. Xiao and X. Wu, J. Alloys Compd., 2019, 772, 465-471.

13 C. Liu, W. Jiang, F. Hu, X. Wu and D. F. Xue, Inorg. Chem. Front., 2018, 5, 835-843.

14 A. K. Singh, D. Sarkar, K. Karmakar, K. Mandal and G. G. Khan, ACS Appl. Mater. Interfaces, 2016, 8, 2078620792 .
15 D. P. Zhao, F. Hu, A. Umar and X. Wu, New J. Chem., 2018, 42, 7399-7406.

16 X. Wu and S. Y. Yao, Nano Energy, 2017, 42, 143-150.

17 J. X. Feng, L. X. Ding, S. H. Ye, X. J. He, H. Xu, Y. X. Tong and G. R. Li, Adv. Mater., 2015, 27, 7051-7057.

18 W. Jiang, F. Hu, Q. Y. Yan and X. Wu, Inorg. Chem. Front., 2017, 4, 1642-1648.

19 Y. Zhao, M. Z. Dai, D. P. Zhao, L. Xiao, X. Wu and F. Liu, CrystEngComm, 2019, 21, 3349-3355.

20 M. J. Xie, Z. C. Xu, S. Y. Duan, Z. F. Tian, Y. Zhang, K. Xiang, M. Lin, X. F. Guo and W. P. Ding, Nano Res., 2018, 11, 216224.

21 C. Liu and X. Wu, Mater. Res. Bull., 2018, 103, 55-62.

22 L. Xing, Y. D. Dong, F. Hu, X. Wu and A. Umar, Dalton Trans., 2018, 47, 5687-5694.

23 G. M. Li, M. Z. Chen, Y. O. Yang, D. Yao, L. Lu, L. Wang, X. F. Xia, W. Lei, S. M. Chen, M. Daniel and Q. L. Hao, Appl. Surf. Sci., 2019, 469, 941-950.

24 H. F. Zhang, C. X. Lu, H. Hou, Y. Y. Ma and S. X. Yuan, J. Alloys Compd., 2019, 797, 970-977.

25 M. H. Chen, Q. X. Ge, M. L. Qi, X. Q. Liang, F. Wang and Q. G. Chen, Surf. Coat. Technol., 2019, 360, 73-77.

26 Y. Gao, S. Chen, D. Cao, G. Wang and J. Yin, J. Power Sources, 2010, 195, 1757-1760.

27 Q. Yang, Z. Y. Lu, Z. Chang, W. Zhu, J. Q. Sun, J. F. Liu, X. M. Sun and X. Duan, RSC Adv., 2012, 2, 1663-1668.

28 P. H. Yang and W. J. Mai, Nano Energy, 2014, 8, 274-290.

29 G. P. Xiong, P. G. He, D. N. Wang, Q. Q. Zhang, T. F. Chen and T. S. Fisher, Adv. Funct. Mater., 2016, 26, 5460-5470.

30 X. Peng, L. L. Peng, C. Z. Wu and Y. Xie, Chem. Soc. Rev., 2014, 43, 3303-3323.

31 B. T. Zhao, L. Zhang, Q. B. Zhang, D. C. Chen, Y. Cheng, X. Deng, Y. Chen, R. Murphy, X. H. Xiong, B. Song, C. P. Wong, M. S. Wang and M. L. Liu, Adv. Energy Mater., 2018, 8, 1702247-1702257.

32 F. Y. Liu, X. Chu, H. T. Zhang, B. B. Zhang, H. Su, L. Jin, Z. X. Wang, H. C. Huang and W. Q. Yang, Electrochim. Acta, 2018, 269, 102-110.

33 X. H. Xiong, D. Ding, D. C. Chen, G. Waller, Y. F. Bu, Z. X. Wang and M. L. Liu, Nano Energy, 2015, 11, 154-161.

34 H. Wang, H. S. Casalongue, Y. Liang and H. Dai, J. Am. Chem. Soc., 2010, 132, 7472-7477.

35 Y. Liu, D. P. Zhao, H. Q. Liu, A. Umar and X. Wu, Chin. Chem. Lett., 2019, 30, 1071-1076.

36 G. Q. Zu, J. Shen, Z. H. Zhang, B. Zhou, X. D. Wang, G. M. Wu and Y. W. Zhang, RSC Adv., 2017, 7, 10583-10591.

37 F. Y. Ning, M. F. Shao, C. L. Zhang, S. M. Xu, M. Wei and X. Duan, Nano Energy, 2014, 7, 134-142.

38 G. M. Li, M. Z. Chen, Y. Ouyang, D. Yao, L. Lu, L. Wang, X. F. Xia, W. Lei, S. M. Chen, M. Daniel and Q. L. Hao, Appl. Surf. Sci., 2019, 469, 941-950.

39 P. Oliva, J. Leonardi and J. F. Laurent, J. Power Sources, 1982, 8, 229-255.

40 S. H. Yang, Y. Y. Liu, Y. F. Hao, X. P. Yang, A. Goddard III William, X. L. Zhang and B. Q. Cao, Adv. Sci., 2018, 5, 1700659. 
41 P. F. Hu, D. P. Zhao, H. Q. Liu, K. F. Chen and X. Wu, CrystEngComm, 2019, 21, 1600-1606.

42 D. M. Xu, H. W. Wang, F. Y. Li, Z. C. Guan, R. Wang, B. B. He, Y. S. Gong and X. L. Hu, Adv. Mater. Interfaces, 2019, 6, 1801506.

43 W. Quan, Y. Y. Xu, Y. T. Wang, S. C. Meng, D. L. Jiang and M. Chen, Appl. Surf. Sci., 2019, 488, 639-647.

44 H. B. Li, M. H. Yu, F. X. Wang, P. Liu, Y. Liang, J. Xiao, C. X. Wang, Y. X. Tong and G. W. Yang, Nat. Commun., 2013, 4, 1894.
45 F. F. Zhu, M. Yan, Y. Liu, H. Shen, Y. Lei and W. D. Shi, J. Mater. Chem. A, 2017, 5, 22782-22789.

46 M. J. Jing, Y. C. Yang, Y. R. Zhu, H. S. Hou, Z. B. Wu and X. B. Ji, Electrochim. Acta, 2014, 141, 234-240.

47 X. Wang, K. Song, R. Yang, X. Y. Jing and J. Wang, ChemistrySelect, 2019, 4, 3878-3883.

48 B. Kirubasankar, P. Palanisamy, S. Arunachalam, V. Murugadoss and S. Angaiah, Chem. Eng. J., 2019, 355, 881-890.

49 T. Liu, L. Y. Zhang, W. You and J. G. Yu, Small, 2018, 14, 1702407. 